e-ISSN: $1984-4255$ ARGUMENTOS

D01: $10.36517 /$ Argumentos.25.12

\title{
A filosofia de Henrique Cláudio de Lima Vaz
}

\author{
The philosophy of Henrique Cláudio de Lima Vaz \\ Cláudia Maria Rocha de Oliveira \\ https://orcid.org/0000-0002-1369-7076 - E-mail: claudiamroliveira@gmail.com
}

\begin{abstract}
RESUMO
O presente artigo possui como objetivo apresentar, em linhas gerais, a proposta filosófica de Henrique Cláudio de Lima Vaz, um dos mais importantes filósofos brasileiros do século XX. Destacaremos três traços importantes que consideramos fundamentais para que possamos compreender de modo adequado a proposta do filósofo jesuíta. Em primeiro lugar, ao seguir a classificação proposta por Ivan Domingues mostraremos em que sentido, Lima Vaz pode ser compreendido como intelectual público. Em seguida, examinaremos em que consiste a dialética, assumida por Lima Vaz como método (caminho) de investigação. Finalmente, num terceiro momento, mostraremos que, ao assumir a dialética como método, Lima Vaz propõe uma articulação entre os movimentos vertical e horizontal, procurando superar a aparente contradição entre a modernidade e o pensamento cristão.
\end{abstract}

Palavras-chave: Intelectual público. Dialética. História. Absoluto.

\begin{abstract}
The purpose of this article is to present, in general lines, the philosophical proposal of Henrique Cláudio de Lima Vaz, one of the most important Brazilian philosophers of the 20th century. We will highlight three important traits that we consider fundamental so that we can properly understand the proposal of the Jesuit philosopher. Firstly, following the classification proposed by Ivan Domingues, we will show in what sense Lima Vaz can be understood as a public intellectual. Then, we will examine how we need understand the dialectic, assumed by Lima Vaz as a method (path) of investigation. Finally, in a third moment,
\end{abstract}


we will show that, by taking dialectics as a method, Lima Vaz proposes an articulation between vertical and horizontal movements, seeking to overcome the apparent contradiction between modernity and Christian thought.

Keyword: Public intelectual. Dialectic. History. Absolute.

\section{Introdução}

Henrique Cláudio de Lima Vaz é um filósofo jesuíta. Ele nasceu em 1921 e faleceu em 2002. Logo após o término da Segunda Guerra mundial, em 1945, ele foi enviado a Roma para estudar teologia e realizar pesquisa de doutorado em Filosofia. Confrontou-se, neste período, com autores que propunham desenvolver uma filosofia e uma teologia cristãs mais atentas às transformações do mundo. Entre os autores que o influenciaram, neste período, podemos citar como exemplos o teólogo Henri de Lubac (1896-1991) e o filósofo Emmanuel Mounier (19051950). Ao retornar ao Brasil, após o período de formação na Europa, Henrique Cláudio de Lima Vaz assume o posto de professor de filosofia, no Escolasticado de Formação dos Jesuítas, em Nova Friburgo.

Contudo, o seu envolvimento, no final da década de cinquenta e início da década de sessenta, com a Juventude Universitária Católica (JUC) fez com que ele fosse transferido, em 1964, para Belo Horizonte. Na capital mineira, Lima Vaz se tornou professor da Universidade Federal de Minas Gerais (UFMG). Nos anos que lecionou na UFMG, entre outras coisas, dedicou-se ao estudo das obras do pensador alemão Georg Hegel (1770-1831). Tornou-se conhecido como um dos principais estudiosos deste filósofo no Brasil. Em 1982, a Faculdade Jesuíta foi transferida para Belo Horizonte. Lima Vaz esteve vinculado a ela até 2002, ano de sua morte.

Neste artigo procuraremos mostrar, em primeiro lugar, que Lima Vaz pode ser definido como intelectual público. Em seguida veremos, que ao desenvolver sua reflexão, ele adota o método dialético. Contudo, o método dialético limavaziano não se confunde com a dialética hegeliana. Finalmente, mostraremos que ao adotar a dialética como método, Lima Vaz propõe repensar a relação entre a modernidade e o pensamento cristão, ou de modo mais direto, a relação entre a história e o absoluto.

\section{Lima Vaz: um intelectual público sui generis}

Em seu livro Filosofia no Brasil: legados e perspectivas, Ivan Domingues classifica o filósofo Henrique Vaz, ao lado de Giannotti e Marilena Chauí, como sendo um intelectual público. Para Domingues, o intelectual público republicano é aquele que se opõe ao "tipo ideal do intelectual colonizado". Trata-se, portanto, de uma "vertente do intelectual cosmopolita, do grego cosmopolites, vem a ser, o intelectual cosmopolita cidadão do mundo". O intelectual público é aquele que se exprime como"membro livre de um Estado ou de uma cidade" (DOMINGUES, 2017, p. 483). Ou ainda, é aquele que "acrescenta à sua formação de scholar e iniciado em filosofia [...] a agenda política [...], circunscrita a um país e definida pela inserção do pensador ou escritor na vida da cidade (polis)" (DOMINGUES, 2017, p. 483). O scholar consiste, de acordo com a classificação proposta por Domingues, num "tipo de intelectual comum ao campo das humanidades, tendo o filólogo e o historiador à frente" (DOMINGUES, 2017, p. 41). Em consequência, pensar Lima Vaz 
como intelectual público supõe reconhecer que estamos diante de um pensador de grande erudição, capaz de realizar exegeses profundas e rigorosas dos textos filosóficos, capaz de situar as grandes questões no interior de uma abordagem histórica. Mas, supõe ir além e pressupor, sobretudo, que estamos diante de um pensador extremamente preocupado com os desafios que são lançados pelo contexto concreto da sociedade e da cultura no qual está inserido.

Ivan Domingues chama atenção para os motivos que fazem de Lima Vaz, ao lado de Giannotti e Marilena Chauí, um intelectual público. No caso das três personalidades, para Domingues, elas podem ser afirmadas como intelectuais públicos não pelo caminho de uma instrumentalização da filosofia, nem de uma transformação da mesma "em arma ideológica". Mas, podem ser considerados como intelectuais públicos por que de algum modo elas se encontram com as questões políticas "no campo da experiência pessoal, como um problema premente ou objeto a mais da reflexão" (DOMINGUES, 2017, p. 485).

Ora, ao seguir Paulo Arantes (2005), Domingues reconhece que, no caso específico de Lima Vaz, estamos diante de um intelectual público completamente sui generis. Trata-se de uma "figura intelectual rigorosamente pública, tão vasta era a irradiação de sua influência, e ao mesmo tempo totalmente privada, tamanha era sua reserva em relação a coisas pessoais, preferindo à publicidade da mídia o completo anonimato da vida monacal" (DOMINGUES, 2017, p. 487).

Embora tenha optado por uma vida de recolhimento, a filosofia de Lima Vaz nunca deixou de lado as questões políticas e sociais. O sistema filosófico que ele desenvolveu, expressão máxima de sua maturidade intelectual, pode ser interpretado como uma tentativa de aprofundar e encontrar luzes para as grandes questões com as quais ele se confrontou ao longo de toda a vida. Atílio Peppe, em tese recentemente defendida na Pontifícia Universidade Católica de São Paulo, afirma que um dos problemas de fundo com o qual Lima Vaz se confrontou ao longo de toda a sua trajetória intelectual é a questão definida por Hegel como sendo a "tragédia do ético". Trata-se, de acordo com Peppe, da contradição teórica e prática caracterizada por uma cisão entre a integração ética e a sociedade moderna. Esta tragédia se revela de modo dramático "no advento massivo do trabalho livre subordinado a interesses predatórios do capital e da tecnocracia" (PEPPE, 2020, p. 60). Ora, a tese de Atílio, nos permite confirmar, que como intelectual público, Lima Vaz era extremamente comprometido com as questões sociais. Ele (aqui uma vírgula foi suprimida) era, sem dúvida, um pensador para quem fazer filosofia de modo rigoroso e coerente supõe grande responsabilidade e atenção com a realidade concreta.

Ao assumir como tarefa, para dizer numa linguagem hegeliana, traduzir o seu tempo no conceito, Lima Vaz assume como método de investigação a dialética. Contudo, a nosso ver, ainda hoje temos dificuldade para compreender o alcance e o significado dessa opção limavaziana.

\section{A dialética como método (caminho) em Lima Vaz}

A partir da década de setenta, Lima Vaz passou a se dedicar de modo bastante intenso ao estudo dos textos de Hegel. Este estudo deu origem a vários cursos sobre Hegel que foram ministrados na UFMG. Vários destes cursos foram gravados. Um projeto coordenado pelo professor João Mac Dowell ${ }^{1}$ e apoiado pela FAPEMIG permitiu que os cursos fossem transcritos. Em 2014, foi publicado um livro fruto deste trabalho de divulgação de material inédito, intitulado $A$ formação do pensamento de Hegel. Em breve, serão publicados mais três livros que tiveram origem a partir da transcrição dos cursos sobre Hegel, ministrados por Lima Vaz, na UFMG.

\footnotetext{
1 Trata-se do projeto “Edições das obras inéditas de Henrique Cláudio de Lima Vaz" que, até 2019, contou com o apoio da FAPEMIG.
} 
Ora, a dedicação de Lima Vaz ao estudo sobre Hegel fez com que ele se tornasse conhecido no Brasil como referência na pesquisa sobre este importante pensador alemão. Um dos reflexos desse reconhecimento é o fato de que, ainda hoje, muitas pessoas ainda identificam Lima Vaz com Hegel. Quando o tema é a dialética, há sempre uma tendência de aproximar o pensador brasileiro do filósofo alemão. Contudo, como mostrou Manuel Moreira (2019), a dialética em Lima Vaz não corresponde ao modelo dialético hegeliano. Uma explicação para essa não correspondência pode ser encontrada, a nosso ver, no fato de que Lima Vaz, ao propor a dialética como método, embora se inspire em Hegel, oferece-nos um modelo de dialética próprio, singular. Esta posição encontra confirmação em um texto publicado por Javier Herrero, a respeito da Antropologia Filosófica. Neste texto Herrero afirma:

Diz-se com frequência que o Pe. Vaz é hegeliano. Certamente que não é o caso. $E$ isto não porque ele se distinga ou se afaste de Hegel em alguns aspectos importantes. É a compreensão do ser na sua totalidade, de início ao fim, que o distingue dele. E dizendo isso está caracterizada a total divergência. É claro que isso não significa que o Pe. Vaz não tenha aprendido e muito de Hegel (HERRERO, 2003, p. 9).

A questão que surge é, então, a seguinte: em que consistiria a singularidade do modelo limavaziano? Qual seria a noção de ser que estaria na base da proposta do filósofo jesuíta? É fundamental recordar que, mesmo antes de se dedicar ao estudo sobre Hegel, Lima Vaz tinha grande estima por Platão. A tese de doutorado defendida por ele, na Pontifícia Universidade Gregoriana em Roma, teve como tema Contemplação e dialética nos diálogos platônicos. Este texto, originalmente escrito em latim, apenas em 2012, foi traduzido e publicado em português. Talvez a dificuldade de acesso a esse trabalho, antes de sua publicação, tenha sido um dos motivos de os pesquisadores quase não associarem a dialética limavaziana com a dialética platônica.

Seja como for, um estudo mais atento dos textos de Lima Vaz não deixa dúvida de que a dialética tal como proposta por ele apenas pode ser adequadamente compreendida se tivermos como horizonte esta dupla fonte de inspiração: as dialéticas platônica e hegeliana. Trata-se na verdade, de um esforço para conciliar estes dois modelos. O primeiro que se caracteriza por um movimento ascendente que conduz à afirmação de uma realidade transcendente, condição última de possibilidade de todo sentido. O segundo que se caracteriza, por sua vez, como um movimento horizontal que procura encontrar, no próprio dinamismo da história, o sentido do todo.

Por trás dessa tentativa de pensar a dialética a partir da intersecção desses dois modelos, o que Lima Vaz tem como fim, a nosso ver, é justamente reconciliar o pensamento cristão com a modernidade. Trata-se, em última instância de uma tentativa de superar a oposição entre a afirmação de uma subjetividade engajada historicamente e, portanto, convocada a assumir existencialmente a responsabilidade pela construção de sentido, e a afirmação de um absoluto real como princípio primeiro de todo a realidade, como condição última de todo o sentido.

Além da influência de Platão e Hegel, é fundamental ter presente, como sinalizou Herrero, que, ao repropor a dialética como ontologia, Lima Vaz assume como desafio atualizar a noção de ser presente no pensamento de Tomás de Aquino. A reflexão limavaziana, portanto, constitui-se como uma reflexão extremamente audaz. Ela pretende ser capaz de articular de um modo profundo os movimentos vertical e horizontal que caracterizam, respectivamente, os modelos dialéticos em Platão em Hegel, assumindo como pano de fundo a metafísica do esse, de Tomás de Aquino. Em consequência, embora busque inspiração na dialética de Hegel, Lima Vaz não é hegeliano. Por outro lado, podemos afirmar também que ele não é um neoplatônico. 
Talvez o mais adequado seria dizer que estamos diante de um filósofo cristão que pretende, em diálogo com a modernidade, repropor de modo criativo, a metafísica de Tomás de Aquino.

Herrero esclarece que Lima Vaz possui um modo especial de compreender a filosofia.

Decisivo para ele é sempre a experiência originária que os grandes filósofos gregos fizeram. [...] E a ontologia grega foi radicalizada por Santo Tomás, ao elevar a pergunta da razão até o nível da existência do todo: qual é o sentido do existir em geral? [...] A partir daí, fazer filosofia significa refazer essa experiência originária nas condições históricas que nos cabe viver. E Hegel é o grande mestre dessa rememoração. É por isso que Platão, Tomás e Hegel foram os três grandes mestres do Pe. Vaz na tarefa de fazer filosofia nos dias de hoje (HERRERO. 2003, p. 9-10).

Não se trata, no entanto, de uma proposta inspirada por sentimento nostálgico. Ao contrário, ela surge a partir do esforço de encontrar saídas para os problemas impostos pela modernidade. Ao buscar reconciliar a tradição cristã com a modernidade, recriar a metafísica de Santo Tomás se apresenta como uma alternativa capaz de superar a oposição entre essencialismo e existencialismo. Trata-se, portanto, de uma reflexão engajada com os desafios históricos que se mostra, ao mesmo tempo, capaz de se abrir a uma verdade que se revela no tempo e para além do tempo.

A influência de Tomás de Aquino se faz presente ao longo de toda a reflexão de Lima Vaz. Ela pode ser indicada na própria compreensão da dialética tal como proposta pelo pensador brasileiro. Quando Lima Vaz afirma que os princípios da limitação eidética e da ilimitação tética são constitutivos do movimento dialético, é possível entrever aqui uma proximidade desses princípios com o movimento da inteligência no ato judicativo, tal como explicitado por Tomás de Aquino. A doutrina da reflexão completa desenvolvida por Tomás, ao distinguir a síntese concretiva da síntese judicativa, oferece-nos uma chave de compreensão para a dialética de Lima Vaz que não pode ser encontrada nem na dialética de Platão, nem na dialética hegeliana. Por síntese concretiva, Tomás de Aquino, segundo Lima Vaz, compreende a síntese que se situa no âmbito epistemológico da "atribuição de uma essência ou 'quididade' universal a um sujeito concreto" (LIMA VAZ, 1997, p. 322). A síntese judicativa, por sua vez, pressupõe a suprassunção do ser predicamental pelo ser transcendental. Ao colocar em evidência, a função tética do juízo ela torna possível a "posição incessante do existir (esse) na afirmação como valor inteligível supremo do real". (LIMA VAZ, 1997, p. 325).

Maria Celeste (2014), em sua obra intitulada Comunidade ética: sobre os princípios ontológicos da vida social em Henrique Cláudio de Lima Vaz, chama a atenção justamente para esse dado fundamental. A dialética em Lima Vaz sofre influência da metafísica de Tomás de Aquino. Não apenas a noção de ser implicada na proposta tem como fonte de inspiração a reflexão do doutor angélico, mas os próprios princípios da dialética seguem a dinâmica própria do ato judicativo explicitada pelo doutor medieval. Portanto, a dialética em Lima Vaz não é hegeliana, nem platônica. Contudo, ela também não é tomasiana. Podemos dizer que ela recolhe contribuições de todas essas propostas, as articula e se constitui de um modo novo.

A obra de Lima Vaz é muito rica. Sempre é possível descobrir campos ainda não explorados e dimensões ainda não adequadamente compreendidas. Peppe (2020, p. 83), ao distinguir a dialética de Lima Vaz da dialética de Hegel e de Marx, chama atenção para a influência que a dialética da ação em Blondel exerceu sobre a reflexão de Lima Vaz. Ao mencionar essa influência blondeliana, Peppe traz à luz algo muito importante, mas, ainda pouco explorado pelos estudiosos do pensamento de Pe. Vaz. Como é possível perceber, uma exegese completa e exaustiva da filosofia lima vaziana ainda não foi realizada. Portanto, a sua reflexão se constitui como um amplo e rico campo de investigação, ainda não completamente explorado. 
Estudos sobre a filosofia de Lima Vaz podem, portanto, nos abrir novas possibilidades de compreender melhor a nossa própria realidade e os desafios com os quais a sociedade e a cultura encontram-se continuamente confrontados. Diante da rica proposta de Lima Vaz, e das várias chaves interpretativas que vão sendo aos poucos exploradas pelos estudiosos de seu pensamento, uma consideração fundamental a respeito da dialética proposta pelo filósofo jesuíta se faz necessária. Para ele, a dialética não se constitui como um conjunto de regras pré-estabelecidas que aplico a realidade para poder compreendê-la. Lima Vaz deixa bastante claro, de modo especial no texto Método e Dialética (2002), que a dialética para ele se constitui como ontologia. Ele também estabelece uma distinção importante entre a noção clássica e a noção moderna de método. Ao assumir a dialética como método, ele sinaliza que a assume como caminho de investigação e busca. Trata-se de um "roteiro de inquirição ou busca (zétesis) a orientar a atividade intelectual com vistas à solução de uma dificuldade (aporia) que se apresentava na reflexão ou, mais geralmente, no diálogo" (LIMA VAZ, 2002, p. 10). Portanto, a noção de método é assumida por Lima Vaz, em sentido clássico. Logo, dialética não é um método que pode ser aplicado. Ela não se confunde com um "conjunto de regras ou conselhos para bem dirigir a razão nas ciências" (LIMA VAZ, 2002, p. 9). Ao contrário, a dialética deve ser compreendida como um caminho de investigação que partindo da multiplicidade do real, identifica um aspecto dessa realidade que será tema de investigação, e procura reconduzir esse aspecto a uma unidade de sentido.

\section{Modernidade e pensamento cristão: uma conciliação possível?}

Ora, como afirmamos, ao procurar superar a oposição entre a dialética platônica, caracterizada pelo movimento vertical, e a dialética hegeliana que se define a partir de um movimento horizontal, Lima Vaz parece querer superar a oposição entre o pensamento cristão e a modernidade. Para que a sua proposta se mostre efetiva, trata-se de articular duas noções em aparente contradição, a saber: as noções de história e de absoluto.

A afirmação cristã do Ipsum Esse subsistens, compreendido como realidade eterna e atemporal, parece se opor à historicidade na qual se desenrola o existir humano. Como sabemos, a modernidade atribuiu ao próprio sujeito a responsabilidade de construir o seu próprio mundo e conduzir por si mesmo as suas próprias ações. Na Fundamentação da Metafísica dos Costumes, por exemplo, Immanuel Kant (1724-1804) se esforça para encontrar fundamento não religioso para as ações morais. A modernidade procura se desvincular da afirmação de um absoluto transcendente como condição de possibilidade da existência humana. Para defender o valor absoluto da pessoa humana, e a sua dignidade, parece ter se tornado necessário desvincular-se da perspectiva cristã que, por sua vez, afirma o Absoluto real como fonte última de todo o sentido.

Ao se confrontar com este cenário, Lima Vaz mostrará que a modernidade não está em contradição com o cristianismo. Para ele, a pessoa humana deve, efetivamente, ser capaz de assumir a responsabilidade pela construção de seu próprio mundo, conquistar a sua liberdade e ter reconhecida a sua dignidade. Contudo, a condição última de possibilidade do ato de ser da pessoa singular encontra-se no Absoluto real, ato puro de existir. As dialéticas de Platão e Hegel, se apresentam, portanto, como ponto de partida a partir do qual Lima Vaz proporá rearticular os vetores da transcendência e da imanência. Porém, a noção de ser que o orienta, como já dissemos, é aquela própria da metafísica do esse, de Tomás de Aquino.

Importante ter presente que, mesmo afirmando a primazia da existência, Lima Vaz não adere ao existencialismo. Para ele, essência e existência devem ser assumidas numa síntese dialética. A partir dela, torna-se possível afirmar o processo de realização da pessoa humana 
como um processo de atualização existencial daquilo que se é como essência. Está na base dessa abordagem de Lima Vaz a afirmação da distinção real entre essência e ser. Para Tomás de Aquino, toda realidade criada, é, ao mesmo tempo, um "aquilo", ou seja, uma realidade que se exprime de modo determinado, e um "é", isto é, um ser que existe em ato. $O$ ato de ser indica perfeição. A essência, capaz de delimitar o "aquilo" de cada realidade, pode ser pensada em termos de potência. Em consequência, à medida que é constituída pela distinção real entre essência e ser, as realidades criadas possuem um ato de ser limitado por uma essência. Neste sentido, Gilson esclarece que "a essência de um ente finito exerce sobre o ato de ser uma influência restritiva, que o impede de ser o Puro Ato de Ser, e faz com que seja o ato finito de ser desta ou daquela essência apenas" (GILSON, 1962, p. 39).

Ora, ao propor recriar a perspectiva de Tomás de Aquino, Lima Vaz defenderá que o ser humano possui estrutura constitutiva. Somos corpo-próprio, psiquismo e espírito. Além disso, o ser humano é constitutivamente um ser de relações. Somos ser-no-mundo, ser-com-os-outros e ser-para-a-transcendência. Estrutura e relações tornam possível pensar o ser humano a partir de uma essência constitutiva, ou seja, tornam possível pensar o ser humano a partir de um eidos, de uma determinação eidética. Contudo, aquilo que somos do ponto de vista da essência, precisamos realizar na existência concreta. Ao atualizar através de atos pessoais aquilo que somos, humanizamo-nos, tornamo-nos nós mesmos, isto é, pessoas.

Ao propor uma ontológica capaz de rearticular essência e existência, Lima Vaz pensa o ser humano como expressividade. Enquanto tal, somos sujeitos capazes de transcender a ordem "natural" e empenhar nossa liberdade "num destino histórico" (LIMA VAZ, 2001, p. 166). Pensar o ser humano como expressividade, supõe pensá-lo, portanto, como intencionalidade consciente, capaz de se compreender como realidade histórica, isto é, que se desenvolve no tempo. Em consequência, o sujeito assume a partir desta perspectiva certo protagonismo. Ele se vê lançado diante do desafio de exercer autenticamente a sua liberdade e, em consequência, de assumir a responsabilidade por suas iniciativas. A história é assumida por Lima Vaz, portanto, no sentido moderno. Ela é compreendida como

o que provoca o advento do mundo como mundo humano" (LIMA VAZ, 2001, p. 198). Com outras palavras, Lima Vaz esclarece que a história pode ser definida como "realidade que presentemente temos em vista: a realidade do existir temporal do homem, enquanto este existir é o existir de um sujeito. (LIMA VAZ, 2001, p. 220),

de um sujeito ativo, criativo, construtor de um mundo e de um tempo propriamente humanos. Contudo, para Lima Vaz a afirmação do ser humano como subjetividade engajada, ou melhor, como ser pensado a partir de uma historicidade constitutiva não está em contradição com o pensamento cristão. O Absoluto real, não limita a criatividade e iniciativa do ser humano. Ao contrário, Ele é condição última de possibilidade de nosso ser encarnado. Além disso, ele se apresenta como polo intencional do dinamismo ilimitado da inteligência e da vontade humanas. Este dinamismo é condição de possibilidade da capacidade humana de transcender a realidade dada e, em consequência, conferir a ela um sentido propriamente humano. Podemos afirmar, então, que, para Lima Vaz, o ser humano apenas pode se afirmar como sujeito, à medida que o Absoluto real se apresenta como origem e fim da própria intencionalidade humana. Modernidade e pensamento cristão, portanto, não estão em contradição. Ao contrário, a proposta cristã pode ajudar a modernidade a conduzir a sua plena realização algumas de suas intuições mais importantes. 


\section{Conclusão}

Como procuramos mostrar neste artigo, Lima Vaz é um filósofo brasileiro que desenvolveu reflexão muito rica. Intelectual público, ele nunca deixou de se interessar pelas questões políticas e sociais de seu tempo. Viveu a filosofia como um modo de vida exigente que implica responsabilidade social. Ao assumir a dialética como método (caminho), propôs um modelo próprio de reflexão. Integrou a esse modelo contribuições de pensadores tais como Platão, Hegel e Tomás de Aquino. Ao articular os movimentos vertical e horizontal que caracterizam, respectivamente, a dialética platônica e hegeliana, pretendeu superar a oposição entre cristianismo e modernidade, procurando mostrar que não há contradição entre a afirmação do Absoluto real, isto é, do Ipsum esse subsistens, e a historicidade da condição humana. Trata-se, portanto, de um pensador brasileiro muito importante, cuja obra merece ser explorada, conhecida e aprofundada. As reflexões de Lima Vaz podem nos ajudar, ainda hoje, a encontrar caminhos para pensar os desafios com os quais a sociedade brasileira vem sendo confrontada.

\section{Referências}

ARANTES, P. Um depoimento sobre o Pe. Vaz. Síntese, v. 32, n. 102, 2005. p. 5-24.

DOMINGUES, I. Filosofia no Brasil: legados e perspectivas. São Paulo: Editora Unesp, 2017.

GILSON, E. A existência na filosofia de S. Tomás. São Paulo: Duas Cidades, 1962.

HERRERO, F. A recriação da tradição na Antropologia Filosófica de Pe. Vaz. Síntese, v. 30, n. 96, 2003. p. 5-12.

KANT, I. Fundamentação da Metafísica dos Costumes. São Paulo: Abril Cultural, 1974.

LIMA VAZ, H. C. A formação do pensamento de Hegel. São Paulo: Loyola, 2014.

LIMA VAZ, H. C. Antropologia Filosófica I. São Paulo: Loyola, 1991.

LIMA VAZ, H. C. Antropologia Filosófica II. São Paulo: Loyola, 1992.

LIMA VAZ, H. C. Contemplação e dialética nos diálogos platônicos. São Paulo: Loyola, 2012.

LIMA VAZ, H. C. Escritos de Filosofia III: Filosofia e Cultura. São Paulo: Loyola, 1997.

LIMA VAZ, H. C. Escritos de filosofia VI: Ontologia e história. São Paulo: Loyola, 2001.

LIMA VAZ, H. C. Método e dialética. In: BRITO, E.; CHANG, L. (Orgs.). Filosofia e método. São Paulo: Loyola, 2002. p. 9-17.

MOREIRA, M. Lima Vaz a transformação da dialética hegeliana. Canal oficial da Rede Katholou de Filosofia no Youtube. Vídeo disponibilizado em 27.jan.2019. Disponível em: https://www.youtube.com/watch?v=YP3xt8Gsin0. Acesso em 01 maio 2020.

OLIVEIRA, C. Metafísica e Ética: a filosofia da pessoa em Lima Vaz como resposta ao niilismo contemporâneo. São Paulo: Loyola, 2013.

PEPPE, A. Trabalho e tecnociência na Ética Filosófica de Henrique Cláudio de Lima Vaz. Tese (Doutorado em Filosofia). São Paulo: Pontifícia Universidade de São Paulo (PUCSP), 2020.

RIBEIRO, E. Reconhecimento ético e virtudes. São Paulo: Loyola, 2012.

SOUSA, M. Comunidade ética: sobre os princípios ontológicos da vida social em Henrique Cláudio de Lima Vaz. São Paulo: Loyola, 2014. 


\section{Sobre a autora}

\section{Cláudia Maria Rocha de Oliveira}

Doutora em Filosofia pela Pontificia Università Gregoriana. Atualmente é professora adjunta e pesquisadora da Faculdade Jesuíta de Filosofia e Teologia.

Recebido em: 25/06/2020.

Aprovado em: 25/08/2020.
Received: 25/06/2020.

Approved: 25/08/2020. 